\title{
Modelling Obsolescence Risk and Taxation in Project Valuation
}

\author{
Vince Hooper ${ }^{1}$, John Pointon ${ }^{2}$ \\ ${ }^{1}$ Xiamen University Malaysia, Kuala Lumpur, Malaysia \\ ${ }^{2}$ University of Plymouth, Plymouth, UK \\ Email: hoovcomm@hotmail.com
}

How to cite this paper: Hooper, V. and Pointon, J. (2019) Modelling Obsolescence Risk, Taxation in Project Valuation. Journal of Mathematical Finance, 9, 286-300. https://doi.org/10.4236/jmf.2019.93017

Received: June 12, 2019

Accepted: August 6, 2019

Published: August 9, 2019

Copyright $\odot 2019$ by author(s) and Scientific Research Publishing Inc. This work is licensed under the Creative Commons Attribution International License (CC BY 4.0).

http://creativecommons.org/licenses/by/4.0/

\section{c) (i) Open Access}

\begin{abstract}
The purpose of this paper is to develop a valuation model for projects, explicitly taking into account the combined effects of taxation and the risk of obsolescence. In the modelling process it is assumed that a project's pre-tax net operating cash flows follow a geometric Brownian motion with a declining trend parameter. Obsolescence risk is introduced by means of a Poisson jump. The risk effects on the tax on flows and tax savings through tax depreciation are then evaluated separately. Through sensitivity analysis it is demonstrated that the expected time to obsolescence can have a more dramatic effect upon valuation than moderate changes in tax depreciation rates and corporate tax rates. This is the first paper ever that realistically models obsolescence risk within the context of taxation. The model can be applied to a wide variety of industrial sectors such as oil \& gas; shipping; real estate; information technology; telecommunications and new energy.
\end{abstract}

\section{Keywords}

Capital Budgeting, Dynamic Programming, Oil and Gas, Shipping, New Energy, Telecommunications, Product Life Cycle, Tax, Uncertainty

\section{Introduction}

Within a purely accounting and finance context, obsolescence is associated with an asset becoming increasingly out of date due to technical and commercial factors. It can be distinguished from depreciation due to the fact that obsolescence originates from events occurring in the firm's environment that are often beyond the control of the firm. Depreciation is the wear and tear or the using up of an asset. The obsolescing of an asset occurs regardless of whether an asset depreciates or not. 
Obsolescence is related to the decline and replacement of useful assets so that ultimately firms can survive within a harsh competitive environment, in the long-run. The importance of obsolescence risk and its quantification has been largely ignored in the research literature. This is despite the crucial role in which the assessment of obsolescence risk plays in virtually every decision made within the firm in one form or another. Obsolescence is a fundamental trait of all systems. All systems, undergo a "lifecycle" and are ultimately replaced by new systems. Indeed, all systems are subject to wear and tear (or depreciation) and unless maintained fall into disrepair, but a system that is maintained can still become obsolete. (NB systems that are not maintained undergo "entropy" and become disorderly).

The two main forms that obsolescence can take are technical and commercial.

"technical obsolescence, that is, the process of becoming increasingly out-of-date and, on a comparative basis, inefficient as a result of technological advances and improvements" "commercial obsolescence, that is the process of becoming redundant through a fall in the market demand for the goods or services in the production of which the respective assets are used" [1]. For the purpose of this theoretical valuation paper, we define obsolescence risk as the risk of asset becoming out of date within a future period of time.

It is hoped that the generic valuation model developed in this paper could be used within a variety of business contexts where there is the risk of obsolescence such as oil \& gas; shipping; real estate; information technology; telecommunications and new energy. In this regard, obsolescence risk is inherently related to the lifecycle of an asset which is brought about by technical and commercial factors. With regard to the strategic management literature, Vernon [2] was the first to analyze the growth of international trade to be driven by product lifecycle parameters. Further, within a multi-national context, Vernon [3] has also applied the concept of obsolescence to the bargaining power a multinational enterprise has with a host country government. When a multinational mining firm first enters a foreign territory, it is in a very strong position to accumulate benefits from host country governments in the form of preferential tax treatment and subsidies. Vernon terms this an "obsolescing bargaining" approach to multinational decision-making. Thomas and Worrall [4] have extended Vernon's [3] observation of the obsolescing bargain and propose that the expected future discounted returns to a multinational company decline over time.

The key variables which influence the degree of obsolescence risk of an asset will vary according to asset type, environmental influences and the extent to which an asset has been maintained. If the upkeep of an asset is not maintained over time then it will obsolete at a faster rate than if it were maintained. Firms that are in a high technology industry with a high rate of environmental flux are likely to have assets which will become obsolete at a faster rate than firms that are not. Therefore, obsolescence is related to asset-specificity.

The rate of obsolescence is affected by technological factors as well as prevailing economic conditions. Technological obsolescence is very apparent for the 
telecommunications industry in particular where there has been an enormous growth in digital communication. For example, in Australia, the government has been phasing out the analogue mobile network which ceased to exist in July 2000. The Australian Federal government has increased competition within the telecommunications sector by reducing the cost of smaller telecommunications companies having access to Telstra's network which will have a long-run effect upon profit margins. This "opening" up of the telecommunications industry to greater competition thus increases the rate of economic obsolescence.

It may be argued that the payback method is a useful technique for telecommunications because of the high rate of obsolescence associated with this industrial sector. This argument revolves around the assumption that the obsolescence horizon is short and errors in using the payback period by not taking into account the time value of money is lessened. With the payback approach, the obsolescence event is assumed to occur within a short interval beyond the payback period which may not be true. The payback method has been heavily criticized because it does not take into account the time value of money. Although the discounted payback method does take into account the time value of money, the obsolescence event is not incorporated into the decision tool because the nature of the cash flows beyond the payback period are not modeled. Our model incorporates obsolescence as a Poisson event. Payback does not incorporate the randomness associated with obsolescence. The model may be considered superior to the payback method because it takes explicit account of the obsolescence risk and its inherent effect on valuation.

Obsolescence is sometimes used synonymously with abandonment. Abandonment of a capital-intensive project may be due to many factors other than obsolescence. These may include expropriation or confiscation of assets by an authority external to the firm other than substantial negative net present values being generated by the project. In financial accounts the costs of abandonment are considered as an extraordinary item [5].

Although we acknowledge that abandonment may be connected with a project becoming obsolete due to commercial or technical reasons, we do not take this approach because the abandonment value of the project depends upon the year of abandonment being known to the decision-maker. It is also noted that abandonment is not adequately described or treated in Australian Accounting Standards and is only referred to in relation to extraordinary items.

For a project, obsolescence can have dramatic effects upon the operating cash flows. Furthermore, if an asset is suddenly scrapped this can have dramatic implications for tax write-offs. So tax benefits may result from obsolescence. This paper is aimed at incorporating into the capital project appraisal the risk of obsolescence and the consequential tax effects.

In capital project appraisal, tax effects can have an influence on cash flows, through tax payments and savings through capital allowances (see, for example, Mole [6] and Moon and Hodges [7]). There are also tax effects on the discount rate, the implications of which have been evaluated by Ashton [8], within the 
framework of the capital asset pricing model. Combinations of projects can result in different marginal tax rates and can be optimized by using mathematical programming (see, for example, Berry and Dyson [9] and Farrar [10]). Empirical evidence from survey work and case studies have shown that tax is often not satisfactorily dealt with in the evaluation of UK projects (Morgan [11] and Hodgkinson [12]). As to multinationals, Hooper [13] found, in his comparative survey, that US multinationals placed more emphasis on the allocation of assets and liabilities in an overall tax minimizing configuration than UK multinationals. Across Europe, Pointon, Farrar and Tucker [14] have simulated the relative tax incentives to capital investment, whilst Pointon [15] introduced a stochastic harmonized tax rate.

It is upon the aspects of stochastic modelling that this paper will also focus. Following methodological expositions by Dixit and Pindyck [16], Pointon [17] developed a lease evaluation model subject to tax rate risk. Boston and Pointon [18] have built stochastic valuation models for technological leaders and followers, in the absence of tax complexities. Pointon and Hooper [19] have modelled the effects of stochastic exchange rate movements and a Poisson jump expropriation risk on a multinational capital project, whilst Pointon [20] has evaluated share price implications of a Poisson jump caused by either a bankruptcy or takeover. Modelling economic variables by Itô processes (Itô [21]), particularly with regard to capital investment, is reflected too in the works of Bertola and Cabellero [22], Demers [23], Dixit [16] and McDonald and Siegel [30]. Geometric Brownian motion applications are found in Black and Scholes [24], Brennan and Schwartz [25] and Cox and Huang [26], whilst combined stochastic processes are used by Merton [27] and Brennan and Schwartz [28]. The approach in this paper follows a dynamic programming methodology (Bellman [29]) applied to the continuous time case for the pre-tax cash flows. This can result in a valuation model based on a linear second-order ordinary differential equation. Its use as an alternative to an options methodology with almost identical results is set out by Dixit and Pindyck [30]. Extensions to the irreversibility argument, in the real options literature, by McDonald and Siegel [31] have been examined by Dixit and Pindyck [30]. Triantis and Hodder [32] have used an options methodology to value a production system that takes into account the flexibility of varying output mix and Tannous [33] has addressed the impact of volume flexibility on the value of automated equipment. Busby and Pitts [34] discuss how industrialists consider flexibility.

In Section 2 the assumptions behind the modelling process are set out. The stochastic trend in the cash flows is separated from the obsolescence risk. The valuation model is presented in Section 3, for which the derivations are relegated to appendices. These derivations involve a linear second-order ordinary differential equation and double integrals. The model application is set out in Section 4. This includes sensitivity tests to evaluate the impact of variations in the expected time to obsolescence, the impact of different corporate tax rates and tax depreciation rates, varying trends in cash flows and the different discount rates. 


\section{Assumptions behind the Modelling}

In valuing pre-tax cash flows the project analyst needs to make some assumptions regarding the nature of those cash flows. Are they declining or increasing? Is there an element of random variation around a trend? If it is reasonable to model an economic series such as a share price as a geometric Brownian motion (Dixit and Pyndyck [30], Pointon, [35]), then it is not unreasonable to model the underlying cash flows in this way (Boston and Pointon [18]). Here it is assumed that the pre-tax net operating cash flow follows a geometric Brownian motion process with a trend parameter. The cash flows would have a lognormal distribution. Hence the log of the cash flows would follow an ordinary Brownian motion process, except for the trend parameter. The variance of the log of the cash flows would be a constant times the length of the time interval. This assumption would be suitable for a project whose risk profile would increase over time. As explained earlier, in practice some project analysts have been inclined to use the payback period instead, as a crude way of dealing with uncertainty over time. Others have sought to use a risk-adjusted discount rate. One advantage of the Brownian motion model is that it separates the risk component from the time value of money for any project, regardless of risk. Another alternative is to apply the Capital Asset Pricing Model. However, published betas are normally based on equity betas, which reflect the equity-financed portion of the returns on a company's overall portfolio of projects. Here the focus is on the impact of obsolescence on an individual project, not on the company as a whole.

The next assumption relates to the uncertainty of the obsolescence factor. It is assumed to be a random event in that during a very small time interval, a project is unlikely to become suddenly obsolete.

A Poisson arrival rate is taken to be the rate at which the obsolescence event occurs. The main characteristic of a Poisson distribution is that it depicts a random process. However, in terms of technological risk, the number of events within a fixed time period would be zero or one. The question is whether project obsolescence is to be or not to be! Thus, in the modelling, any obsolescence will be treated as a Poisson jump, a random shock. Because of tax rules relating to asset disposals, the tax effects of a sudden loss in value, resulting in asset disposal can be substantial. Hence a major factor under consideration will be the consequential tax effects. However, for the moment let us ignore the tax effects.

\section{Valuing the Project under Obsolescence Risk}

For an infinite project the present value of the pre-tax net operating cash flows, $V$, is given by the current pre-tax net operating cash flow, $W$, capitalized at the sum of the declining trend parameter, a, the arrival rate of obsolescence, $\lambda$, and the cost of capital, $k$, (see Appendix 1):

$$
V=W /(a+\lambda+k)
$$

However, given a maximum operating life of $N$ years, the present value of the net operating cash flows, $V_{C}$, is less than the value under the infinite model, and 
is given by (see Appendix 2):

$$
V_{C}=\frac{W}{a+\lambda+k}\left(1-\mathrm{e}^{-(k+a+\lambda) N}\right)
$$

The tax effects on these flows need to take into account the tax payment dates on each year's cash flows. There will also be an associated probability of obsolescence occurring during a given year, in which case the cash flows will be reduced and consequently there will be a reduced tax liability. The Poisson arrival rate will therefore have an impact on the tax effects of the cash flows. A further feature that needs to be accommodated is the structure of tax payment dates which do not usually coincide with the timing of the pre-tax cash flows. Obsolescence effects in future years need to reflect the probability of survival in earlier years. It follows (see Appendix 3) that the present value of all the taxes on the cash flows for years 1 to $N$, denoted $V_{T}$, is given by:

$$
V_{T}=\frac{T W}{a}\left(\frac{\lambda}{a+\lambda}+\mathrm{e}^{a+\lambda}\left[1-\frac{\lambda}{a+\lambda}\right]-1\right) \mathrm{e}^{-(L-1) k}\left(\sum_{n=1}^{N} \mathrm{e}^{-(a+\lambda+k) n}\right)
$$

Let us now consider the tax depreciation (capital allowance) implications of the investment. On the basis of the diminishing balance method applied to the tax depreciation charge on an asset, let us assume that any remaining balance on disposal is tax deductible. This applies, for example, to losses on disposal of Australian capital investments in plant and machinery and similarly on UK short-life assets. For convenience we shall assume that there are zero proceeds on disposal.

If there is no obsolescence the tax depreciation allowances simply reduce year by year (see Appendix 4) as set out in Table 1 and Table 2 . The probability that obsolescence has not yet occurred is also shown. The tax implications of obsolescence are principally that there may be a substantially valuable tax write-off. If obsolescence occurs in the first year there would be a tax allowance of the full cost. The tax allowances and probabilities of occurrence are shown in Table 2.

The discounted value of the tax savings due to tax depreciation is given by the tax rate times the sum of:

Table 1. Tax depreciation with no obsolescence.

\begin{tabular}{ccc}
\hline Year & $\begin{array}{c}\text { Allowance if No } \\
\text { Obsolescence Risk }\end{array}$ & $\begin{array}{c}\text { Probability of No Obsolescence } \\
\text { in Given Year or Previous Years }\end{array}$ \\
\hline 1 & $I_{0} r$ & $\mathrm{e}^{-\lambda}$ \\
2 & $I_{0} r(1-r)$ & $\mathrm{e}^{-2 \lambda}$ \\
3 & $I_{0} r(1-r)^{2}$ & $\mathrm{e}^{-3 \lambda}$ \\
$1<t<N$ & $I_{0} r(1-r)^{t-1}$ & $\mathrm{e}^{-\lambda t}$ \\
$N$ & $I_{0}-\sum_{x=1}^{N-1} I_{0} r(1-r)^{x-1}$ & $\mathrm{e}^{-\lambda \lambda}$ \\
\hline
\end{tabular}


Table 2. Tax depreciation with obsolescence risk.

\begin{tabular}{|c|c|c|}
\hline Year & $\begin{array}{l}\text { Allowance if Obsolescence } \\
\text { Occurs During the Year }\end{array}$ & $\begin{array}{c}\text { Probability of Obsolescence } \\
\text { During the Year }\end{array}$ \\
\hline 1 & $I_{0}$ & $1-\mathrm{e}^{-\lambda}$ \\
\hline 2 & $I_{0}-I_{0} r$ & $\mathrm{e}^{-\lambda}-\mathrm{e}^{-2 \lambda}$ \\
\hline 3 & $I_{0}-\sum_{x=1}^{2} I_{0} r(1-r)^{x-1}$ & $\mathrm{e}^{-2 \lambda}-\mathrm{e}^{-3 \lambda}$ \\
\hline $1<t<N$ & $I_{0}-\sum_{r=1}^{t-1} I_{0} r(1-r)^{x-1}$ & $\mathrm{e}^{-\lambda(t-1)}-\mathrm{e}^{-\lambda t}$ \\
\hline$N$ & $I_{0}-\sum^{N-1} I_{0} r(1-r)^{x-1}$ & $\mathrm{e}^{-\lambda(N-1)}-\mathrm{e}^{-\lambda N}$ \\
\hline
\end{tabular}

1) The discounted annual allowance with no obsolescence risk times the probability of no obsolescence in the given year nor in previous years, and,

2) The discounted balancing allowance, if obsolescence occurs during the year, times the probability of obsolescence during the year.

It follows that the present value of the tax savings from the tax depreciation, denoted $V_{S}$ is given by:

$$
\begin{aligned}
& V_{S}=T\left\{\left[I_{0} r\left(\mathrm{e}^{-\lambda}\right)+I_{0}\left(1-\mathrm{e}^{-\lambda}\right)\right] \mathrm{e}^{-L k}\right. \\
& +\sum_{n=2}^{N-1} \mathrm{e}^{-(L+n-1) k}\left(I_{0} r(1-r)^{n-1} \mathrm{e}^{-\lambda n}+\left[I_{0}-\sum_{x=1}^{n-1} I_{0} r(1-r)^{x-1}\right]\left[\mathrm{e}^{-\lambda(n-1)}-\mathrm{e}^{-\lambda n}\right]\right) \\
& \left.+\mathrm{e}^{-(L+N-1) k}\left(I_{0}-\sum_{x=1}^{N-1} I_{0} r(1-r)^{x-1}\right) \mathrm{e}^{-\lambda(N-1)}\right\} .
\end{aligned}
$$

Finally, the total after-tax net present value of the project subject to obsolescence risk is given by:

$$
N P V \equiv-I_{0}+V_{C}+V_{S}-V_{T}
$$

i.e. deduct the outlay; add the present value of the pre-tax net operating cash flows; add the present value of the tax savings from tax depreciation; and deduct the present value of the taxes on the cash flows. So:

$$
\begin{aligned}
& N P V=-I_{0}+\frac{W}{k+a+\lambda}\left(1-\mathrm{e}^{-(k+a+\lambda) N}\right)+T\left\{\left[I_{0} r\left(\mathrm{e}^{-\lambda}\right)+I_{0}\left(1-\mathrm{e}^{-\lambda}\right)\right] \mathrm{e}^{-L k}\right. \\
& +\sum_{n=2}^{N-1} \mathrm{e}^{-(L+n-1) k}\left(I_{0} r(1-r)^{n-1} \mathrm{e}^{-\lambda n}+\left[I_{0}-\sum_{x=1}^{n-1} I_{0} r(1-r)^{x-1}\right]\left[\mathrm{e}^{-\lambda(n-1)}-\mathrm{e}^{-\lambda n}\right]\right) \\
& \left.+\mathrm{e}^{-(L+N-1) k}\left(I_{0}-\sum_{x=1}^{N-1} I_{0} r(1-r)^{x-1}\right) \mathrm{e}^{-\lambda(N-1)}\right\} \\
& -\frac{T W}{a}\left(\frac{\lambda}{a+\lambda}+\mathrm{e}^{a+\lambda}\left[1-\frac{\lambda}{a+\lambda}\right]-1\right) \mathrm{e}^{-(L-1) k}\left(\sum_{n=1}^{N} \mathrm{e}^{-(a+\lambda+k) n}\right) .
\end{aligned}
$$

\section{Application}

Consider an asset costing $\$ 100,000$ with a maximum operating life of 5 years. 
The expected time to obsolescence is also five years, i.e. $\lambda \quad 0.2$. The tax depreciation rate is 40 per cent and the corporate tax rate is 33 per cent. The initial cash flows are at an annual rate of $\$ 48,000$, with a declining trend of 5 per cent per annum. The continuous discount rate is 10 per cent per annum. The tax lag from the beginning of the relevant year is 13 months on 85 per cent of the estimated liability and 20.5 months on the remaining 15 per cent, so effectively the tax lag is split, i.e.:

$$
\mathrm{e}^{-L k} \equiv 0.85 \mathrm{e}^{-\frac{13}{12} k}+0.15 \mathrm{e}^{-\frac{20.5}{12} k}
$$

when $k=10$ percent, $\mathrm{e}^{-L k}=0.889173$.

By using a spreadsheet, it was computed that the net present value is $\$ 5415$.

A sensitivity analysis was performed around this base case, the results of which are set out in Table 3. The expected time to obsolescence can have a dramatic effect upon the net present value. When the time horizon changes from

Table 3. Sensitivity analysis.

\begin{tabular}{|c|c|}
\hline Variation in Parameter Estimates & Net Present Value \$ \\
\hline \multicolumn{2}{|l|}{ Expected time to obsolescence: } \\
\hline Never & 42,799 \\
\hline 10 years & 21,340 \\
\hline 8 years & 16,914 \\
\hline 5 years & 5415 \\
\hline 4 years & $(1000)$ \\
\hline \multicolumn{2}{|l|}{ Corporate tax rate: } \\
\hline 0 & 13,311 \\
\hline $30 \%$ & 6133 \\
\hline $33 \%$ & 5415 \\
\hline $36 \%$ & 4697 \\
\hline \multicolumn{2}{|l|}{ Tax depreciation rate: } \\
\hline $30 \%$ & 4704 \\
\hline $35 \%$ & 5076 \\
\hline $40 \%$ & 5415 \\
\hline $45 \%$ & 5724 \\
\hline \multicolumn{2}{|l|}{ Trend in cash flows: } \\
\hline $10 \%$ declining & $(1184)$ \\
\hline $5 \%$ declining & 5415 \\
\hline $1 \%$ increasing & 13,022 \\
\hline $5 \%$ increasing & 21,773 \\
\hline $10 \%$ increasing & 31,939 \\
\hline \multicolumn{2}{|l|}{ Discount rate: } \\
\hline $6 \%$ & 12,566 \\
\hline $8 \%$ & 8899 \\
\hline $10 \%$ & 5415 \\
\hline $12 \%$ & 2102 \\
\hline
\end{tabular}


five years to four years the net present value changes from plus $\$ 5415$ to minus $\$ 1000$ (see Table 3). The tax rate has a more moderate effect on the net present value, at least compared with obsolescence risk. However, if the corporate tax rate were zero the net present value would increase to $\$ 13,311$, ceteris paribus (see Table 3). The tax depreciation rate itself does not affect the net present value by very much, the project being fairly invariant to this parameter effect.

Changing the estimates of the trend in the cash flows, not surprising affects the net present value more than reasonable changes in corporate tax rates or tax depreciation rates. Finally, the net present value of the project is sensitive to changes in the discount rate.

\section{Conclusions}

A valuation model has been developed for a project subject to obsolescence risk. The pre-tax net operating cash flows followed a geometric Brownian motion, whilst obsolescence risk was introduced by a Poisson jump. Using a dynamic programming methodology a second-order differential equation was set up to value the pre-tax cash flows. Tax effects were evaluated separately. The effect of obsolescence risk on a balancing allowance is applied to an Australian investment in plant and machinery. Through sensitivity analysis it is demonstrated that the expected time to obsolescence can have a more dramatic effect upon valuation than moderate changes in tax depreciation rates and corporate tax rates.

Points where the model could be extended include, for example, where the asset has some residual value or, if it becomes obsolete, the asset may earn some more income at a reduced level for a period of time.

The model formulated in this paper could be applied to many business decisions in industries such as oil \& gas; shipping; real estate; information technology; telecommunications and new energy, because all entities become obsolete. Thus the model has applications in marketing and corporate strategy such as product life cycle. The model could be applied in human resource management within the context that some workers become redundant and valuing intangibles with modifications. The model could be also applied in an international business setting to model the negotiating power that a multinational corporation has with a host country government.

\section{Conflicts of Interest}

The authors declare no conflicts of interest regarding the publication of this paper.

\section{References}

[1] ASCPA (1998) Members' Handbook. AAS 4.

[2] Vernon, R. (1966) International Investment and International Trade in the Product Cycle. Quarterly Journal of Economics, 80, 190-207. 
https://doi.org/10.2307/1880689

[3] Vernon, R. (1971) Sovereignty at Bay: The Multinational Spread of US Enterprises. Basic Books, New York. https://doi.org/10.1002/tie.5060130401

[4] Thomas, J. and Worrall, T. (1994) Foreign Direct Investment and the Risk of Expropriation. Review of Economic Studies, 61, 81-108. https://doi.org/10.2307/2297878

[5] ASCPA (1998) Members' Handbook. AAS 1. AASB 1018.

[6] Mole, R. (1990) Post-Tax Capital Investment Appraisal: Plant and Machinery. Accounting and Business Research, 20, 123-134. https://doi.org/10.1080/00014788.1990.9728870

[7] Moon, P. and Hodges, S. (1989) Implications of the Recent Tax Changes for Corporate Capital Investment. Journal of Business Finance and Accounting, 16, 25-39. https://doi.org/10.1111/j.1468-5957.1989.tb00002.x

[8] Ashton, D.J. (1989) The Cost of Capital and the Imputation Tax System. Journal of Business Finance and Accounting, 16, 75-88. https://doi.org/10.1111/j.1468-5957.1989.tb00005.x

[9] Berry, R.H. and Dyson, R.G. (1979) A Mathematical Programming Approach to Taxation-Induced Interdependencies in Investment Appraisal. Journal of Business Finance and Accounting, 6, 425-441. https://doi.org/10.1111/j.1468-5957.1979.tb01105.x

[10] Farrar, S. (1994) Taxation and Capital Investment Appraisal: A Mathematical Programming Approach. In: Pointon, J., Ed., Issues in Business Taxation, Aldershot, Wiltshire, 43-81.

[11] Morgan, E.J. (1987) Corporate Taxation and Investment: The Implications of the 1984 Tax Reform Act. Gower, Aldershot.

[12] Hodgkinson, L. (1989) Taxation and Corporate Investment. Chartered Institute of Management Accountants, London.

[13] Hooper, V. (1994) Multinational Capital Budgeting and Finance Decisions. In: Pointon, J., Ed., Issues in Business Taxation, Avebury, Aldershot, 211-225.

[14] Pointon, J., Farrar, S. and Tucker, J. (1996) European Taxation and Capital Investment. European Journal of Finance, 2, 57-76.

https://doi.org/10.1080/135184796337607

[15] Pointon, J. (1997) Corporate Tax Harmonization: Implications for Investment in Plant and Machinery. Paper Presented at British Accounting Association National Conference, Birmingham.

[16] Dixit, A.K. (1991) Analytical Approximations in Models of Hysterisis. Review of Economic Studies, 58, 141-151. https://doi.org/10.2307/2298051

[17] Pointon, J. (1996) Taxation and Lease Evaluation under Uncertainty. Paper Presented at British Accounting Association National Conference, Cardiff.

[18] Boston, J. and Pointon, J. (1999) Valuation under Technological Change. Journal of the Operational Research Society, 50, 255-262. https://doi.org/10.1057/palgrave.jors.2600703

[19] Pointon, J. and Hooper, V. (1995) Exchange Rate and Expropriation Risk in Multinational Capital Budgeting. International Journal of Business Studies, 3, 81-88.

[20] Pointon, J. (1997) Stochastic Modelling and Financial Shocks. In: Atrill, P. and Lindley, L., Eds., Issues in Accounting and Finance, Avebury, Aldershot, 273-282. https://doi.org/10.4324/9780429444241-15 
[21] Itô, K. (1965) On Stochastic Differential Equations. Memoirs of the American Mathematical Society, 4, 1-51.

[22] Bertola, G. and Caballero, R.J. (1994) Irreversibility and Aggregate Investment. Review of Economic Studies, 61, 223-246. https://doi.org/10.2307/2297979

[23] Demers, M. (1991) Investment under Uncertainty, Irreversibility and the Arrival of Information over Time. Review of Economic Studies, 58, 333-350. https://doi.org/10.2307/2297971

[24] Black, F. and Scholes, M. (1973) The Pricing of Options and Corporate Liabilities. Journal of Political Economy, 81, 637-659. https://doi.org/10.1086/260062

[25] Brennan, M.J. and Schwartz, E.S. (1977) Convertible Bonds: Valuation and Optimal Strategies for Call and Conversion. Journal of Finance, 32, 1699-1715. https://doi.org/10.1111/j.1540-6261.1977.tb03364.x

[26] Cox, J.C. and Huang, C. (1989) Optimal Consumption and Portfolio Policies When Assets Follow a Diffusion Process. Journal of Economic Theory, 49, 33-83. https://doi.org/10.1016/0022-0531(89)90067-7

[27] Merton, R.C. (1976) Option Pricing When Underlying Stock Returns Are Discontinuous. Journal of Financial Economics, 20, 125-144. https://doi.org/10.1016/0304-405X(76)90022-2

[28] Brennan, M.J. and Schwartz, E.S. (1982) Consistent Regulatory Policy under Uncertainty. Bell Journal of Economics, 13, 507-521. https://doi.org/10.2307/3003470

[29] Bellman, R. (1957) Dynamic Programming. Princeton University Press, Princeton.

[30] Dixit, A.K. and Pindyck, R.S. (1994) Investment under Uncertainty. Princeton University Press, Princeton.

[31] McDonald, R. and Siegel, D. (1986) The Value of Waiting to Invest. Quarterly Journal of Economics, 101, 707-728. https://doi.org/10.2307/1884175

[32] Triantis, A.J. and Hodder, J.E. (1990) Valuing Flexibility as a Complex Option. Journal of Finance, 45, 549-565. https://doi.org/10.1111/j.1540-6261.1990.tb03702.x

[33] Tannous, G.F. (1996) Capital Budgeting for Volume Flexible Equipment. Decision Science, 27, 159-184. https://doi.org/10.1111/j.1540-5915.1996.tb01714.x

[34] Busby, J.S. and Pitts, C.G.C. (1996) Real Options in Practice: An Exploratory Study of How Decision-Makers Think about Flexibility. Warwick Business School Research Bureau, Coventry, No. 210.

[35] Pointon, J. (1998) Share Valuation under Geometric Brownian Motion with a Poisson Imputation Tax Change. Journal of Business Finance and Accounting, 25, 103-113. https://doi.org/10.1111/1468-5957.00179

[36] Wagner, H.M. (1975) Principles of Operations Research: With Applications to Managerial Decisions. Prentice-Hall, London. 


\section{Appendix 1}

Valuing the pre-tax cash flows under an infinite production model

Suppose that the pre-tax net operating cash flow $W$ follows a geometric Brownian motion process with a decreasing trend parameter, such that:

$$
\mathrm{d} W=-a W \mathrm{~d} t+\sigma W \mathrm{~d} z
$$

where

$$
\begin{aligned}
& a=\text { the decreasing trend parameter, } \\
& t=\text { time, } \\
& \begin{array}{l}
\sigma=\text { the standard deviation parameter, } \\
\mathrm{d} z=v(\mathrm{~d} t)^{1 / 2}, \text { and }
\end{array} \\
& v=\text { the standard normal variate. }
\end{aligned}
$$

Using a dynamic programming methodology (Bellman [29]) we can set up a differential equation (following Dixit and Pindyck [31]) to represent the valuation relationship for a small time period $\mathrm{d} t$ and hence derive the present value of the net operating cash flows, denoted $V$.

If obsolescence occurs during $d t$, the end of period value of the project, ignoring tax effects, is assumed to be zero. The probability of occurrence during $d t$ is $\lambda \mathrm{d} t$, where $\lambda$ is the Poisson arrival rate. The main attributes of the Poisson distribution are: that the probability of an arrival does not depend on the moment in time but on the length of the time interval and that the maximum of only one arrival can occur during a sufficiently small time interval (Wagner [36], p. 860).

Now, if obsolescence does not occur during $\mathrm{d} t$, the value of the cash flows at the end of $\mathrm{d} t$ will equal the value at the beginning of the period $\mathrm{d} t$, denoted $V$, plus $\mathrm{d} V$, the change in value during $\mathrm{d} t$. But, using Itô's [21] lemma under the geometric Brownian motion:

$$
E(\mathrm{~d} V)=-\frac{\mathrm{d} V}{\mathrm{~d} W} a W \mathrm{~d} t+\frac{1}{2} \frac{\mathrm{d}^{2} V}{\mathrm{~d} W^{2}} \sigma^{2} W^{2} \mathrm{~d} t
$$

However, to derive the pre-tax value of the cash flows at the beginning of period $d t$ we need to take:

1) the pre-tax cash flow during $\mathrm{d} t$, denoted $W$, and add

2) the expected value at the end of $\mathrm{d} t$, i.e. $V+E(\mathrm{~d} V)$, discounted at a continuous rate denoted $k$ and multiplied by the probability of no obsolescence occurring, i.e. $(1-\lambda \mathrm{d} t)$.

Therefore:

$$
V=W \mathrm{~d} t+\left\{V-\frac{\mathrm{d} V}{\mathrm{~d} W} a W \mathrm{~d} t+\frac{1}{2} \frac{\mathrm{d}^{2} V}{\mathrm{~d} W^{2}} \sigma^{2} W^{2} \mathrm{~d} t\right\} \frac{1-\lambda \mathrm{d} t}{1+k \mathrm{~d} t}
$$

This reduces to:

$$
\frac{1}{2} \frac{\mathrm{d}^{2} V}{\mathrm{~d} W^{2}} \sigma^{2} W^{2}-\frac{\mathrm{d} V}{\mathrm{~d} W} a W-(\lambda+k) V=-W
$$

This is a non-homogeneous second-order linear ordinary differential equa- 
tion. The solution to the homogeneous part is zero, ignoring speculation and non-economic solutions (see Dixit and Pindyck [31]). Since the right-hand side is linear in $\mathrm{W}$ we can introduce a linear trial function to help determine a solution. Setting $V=m W+c, \mathrm{~d} V / \mathrm{d} W=m$ and $\mathrm{d}^{2} V / \mathrm{d} W^{2}=0$, for $m, c$ constants. Substitution in (A4) produces:

$$
0-m a W-(\lambda+k)(m W+c)=-W
$$

We can choose $c=0$ and $m=1 /(a+\lambda+k)$ as a solution. But, $V=m W+c$. Hence:

$$
V=W /(a+\lambda+k)
$$

\section{Appendix 2}

\section{Adjusting the model for a finite productive life}

The infinite model overvalues a project whose productive life, $N$ years, is less than infinite. If obsolescence occurs up to time $N$, the infinite model overvalues the project by zero, with probability $\int_{0}^{N} \lambda \mathrm{e}^{-\lambda y} \mathrm{~d} y$. But if obsolescence occurs up to time $y>N$, then the infinite model overvalues the project by $\int_{N}^{y} W \mathrm{e}^{-a t} \mathrm{e}^{-k t} \mathrm{~d} t$ with probability $\int_{N}^{\infty} \lambda \mathrm{e}^{-\lambda y} \mathrm{~d} y$. Hence the overvaluation, denoted $V^{*}$, is

$$
V^{*}=\int_{N}^{\infty} \lambda \mathrm{e}^{-\lambda y}\left(W \int_{N}^{y} \mathrm{e}^{-a t} \mathrm{e}^{-k t} \mathrm{~d} t\right) \mathrm{d} y
$$

Therefore:

$$
V^{*}=\frac{W \mathrm{e}^{-(a+k+\lambda) N}}{a+k+\lambda}
$$

Therefore, for a maximum operating life of $N$ years, the present value of the pre-tax net operating cash flows, denoted $V_{c}$, is:

$$
V_{c} \equiv V-V^{*}=\frac{W}{k+a+\lambda}\left(1-\mathrm{e}^{-(k+a+\lambda) N}\right)
$$

\section{Appendix 3}

\section{Valuing the taxes on the cash flows}

The tax payment on the first year's cash flows amounts to $T \int_{0}^{1} W \mathrm{e}^{-a t} \mathrm{~d} t$, if there is no obsolescence. The associated probability is $\mathrm{e}^{-\lambda}$. But if obsolescence at time yoccurs during year 1 , the associated tax effects will be $T W \int_{0}^{y} \mathrm{e}^{-a t} \mathrm{~d} t$ with probability $\int_{0}^{1} \lambda \mathrm{e}^{-\lambda y} \mathrm{~d} y$, i.e. a probability of $1-\mathrm{e}^{-\lambda}$. Given a tax lag of $L$ years from the beginning of the year until the tax payment date, the present value of the tax 
payment on the first year's cash flow is:

$$
\mathrm{e}^{-\lambda}\left(T \int_{0}^{1} W \mathrm{e}^{-a t} \mathrm{~d} t\right) \mathrm{e}^{-L k}+\int_{0}^{1} \lambda \mathrm{e}^{-\lambda y}\left(\mathrm{e}^{-L k} T W \int_{0}^{y} \mathrm{e}^{-a t} \mathrm{~d} t\right) \mathrm{d} y
$$

Let us now consider year 2. Obsolescence may have already occurred in year 1 with a probability of $\int_{0}^{1} \lambda \mathrm{e}^{-\lambda y} \mathrm{~d} y=1-\mathrm{e}^{-\lambda}$, or may occur in year 2 with a probability $\int_{1}^{2} \lambda \mathrm{e}^{-\lambda y} \mathrm{~d} y=\mathrm{e}^{-\lambda}-\mathrm{e}^{-2 \lambda}$, or the project may survive year 2 with a probability of $\mathrm{e}^{-2 \lambda}$. The total probability is:

$$
\left(1-\mathrm{e}^{-\lambda}\right)+\left(\mathrm{e}^{-\lambda}-\mathrm{e}^{-2 \lambda}\right)+\mathrm{e}^{-2 \lambda}=1 .
$$

The tax on the second year's cash flow is zero with probability $\left(1-\mathrm{e}^{-\lambda}\right)$, $T \int_{1}^{y} W \mathrm{e}^{-a t} \mathrm{~d} t$ with probability $\int_{1}^{2} \lambda \mathrm{e}^{-\lambda y} \mathrm{~d} y$, and $T \int_{1}^{2} W \mathrm{e}^{-a t} \mathrm{~d} t$ with probability $\mathrm{e}^{-2 \lambda}$. The tax lag from the beginning of the first year is now $1+L$. Therefore, the present value of the tax on the second year's cash flow is:

$$
\mathrm{e}^{-(L+1) k}\left(\int_{1}^{2} \lambda \mathrm{e}^{-\lambda y}\left(T \int_{1}^{y} W \mathrm{e}^{-a t} \mathrm{~d} t\right) \mathrm{d} y+T \mathrm{e}^{-2 \lambda} \int_{1}^{2} W \mathrm{e}^{-a t} \mathrm{~d} t\right)
$$

For the third year the tax is zero with probability $\left(1-\mathrm{e}^{-2 \lambda}\right), T \int_{2}^{y} W \mathrm{e}^{-a t} \mathrm{~d} t$ with probability $\int_{2}^{3} \lambda \mathrm{e}^{-\lambda y} \mathrm{~d} y$ and $T \int_{2}^{3} W \mathrm{e}^{-a t} \mathrm{~d} t$ with probability $\mathrm{e}^{-3 \lambda}$. Therefore the present value of the tax on the third year's cash flow is:

$$
\mathrm{e}^{-(L+2) k}\left(\int_{2}^{3} \lambda \mathrm{e}^{-\lambda y}\left(T \int_{2}^{y} W \mathrm{e}^{-a t} \mathrm{~d} t\right) \mathrm{d} y+T \mathrm{e}^{-3 \lambda} \int_{2}^{3} W \mathrm{e}^{-a t} \mathrm{~d} t\right)
$$

In general, for the nth year's cash flow $(n<N)$, the present value of the associated tax is:

$$
\mathrm{e}^{-(L+n-1) k}\left(\int_{n-1}^{n} \lambda \mathrm{e}^{-\lambda y}\left(T \int_{n-1}^{y} W \mathrm{e}^{-a t} \mathrm{~d} t\right) \mathrm{d} y+T \mathrm{e}^{-n \lambda} \int_{n-1}^{n} W \mathrm{e}^{-a t} \mathrm{~d} t\right) .
$$

Thus the present value of all the taxes on cash flows for years 1 to $N$, denoted as $V_{T}$, is given by:

$$
V_{T}=\sum_{n=1}^{N}\left\{\mathrm{e}^{-(L+n-1) k}\left[\int_{n-1}^{n} \lambda \mathrm{e}^{-\lambda y}\left(T \int_{n-1}^{y} W \mathrm{e}^{-a t} \mathrm{~d} t\right) \mathrm{d} y+T \mathrm{e}^{-n \lambda} \int_{n-1}^{n} W \mathrm{e}^{-a t} \mathrm{~d} t\right]\right\}
$$

i.e.

$$
V_{T}=\sum_{n=1}^{N}\left\{\mathrm{e}^{-(L+n-1) k}\left[\frac{T W \mathrm{e}^{-(a+\lambda) n}}{a}\left(\frac{\lambda}{a+\lambda}+\mathrm{e}^{a+\lambda}\left[1-\frac{\lambda}{a+\lambda}\right]-1\right)\right]\right\}
$$

Which may be further simplified to:

$$
V_{T}=\frac{T W}{a}\left(\frac{\lambda}{a+\lambda}+\mathrm{e}^{a+\lambda}\left[1-\frac{\lambda}{a+\lambda}\right]-1\right) \mathrm{e}^{-(L-1) k}\left(\sum_{n=1}^{N} \mathrm{e}^{-(a+\lambda+k) n}\right)
$$




\section{Appendix 4}

\section{Valuing the tax depreciation effects}

Given no obsolescence risk and an asset cost of $I_{0}$, the annual allowances at the rate $r$ per annum form a geometric progression:

$$
I_{0} r, I_{0} r(1-r), I_{0} r(1-r)^{2}, \cdots, I_{0} r(1-r)^{j-1},
$$

where $j$ represents the year of allowance.

If obsolescence occurs during the first year there is a tax allowance of the full cost, i.e. $I_{0}$. However, if obsolescence occurs during the second year, there has already been a tax allowance of $I_{0} r$ in the first year, and so the balancing allowance in the second year is $I_{0}-I_{0} r$. Obsolescence in the third year would have implied tax allowances during the first two years summing to:

$$
I_{0} r+I_{0} r(1-r)=\sum_{x=1}^{2} I_{0} r(1-r)^{x-1} \text {. So if obsolescence occurs during the third }
$$

year the balancing allowance would be $I_{0}-\sum_{x=1}^{2} I_{0} r(1-r)^{x-1}$. In general, for obsolescence during the year ended at time $t>1$, the balancing allowance would be:

$$
I_{0}-\sum_{x=1}^{t-1} I_{0}(1-r)^{x-1}
$$

The associated probability of obsolescence before time $t$ is:

$$
P_{t}=\int_{0}^{t} \lambda \mathrm{e}^{-\lambda y} \mathrm{~d} y \equiv 1-\mathrm{e}^{-\lambda t},
$$

and the probability of no obsolescence before time $t$ is simply $\mathrm{e}^{-\lambda t}$. The probability of obsolescence during the year ended at time $t$ is:

$$
\int_{t-1}^{t} \lambda \mathrm{e}^{-\lambda y} \mathrm{~d} y \equiv \mathrm{e}^{-\lambda(t-1)}-\mathrm{e}^{-\lambda t}
$$

The discount factor associated with the tax on the $n$th year's cash flow is $\mathrm{e}^{-(L+n-1) k}$.

If the asset survives as far as the year $N$ then the balancing allowance of $I_{0}-\sum_{x=1}^{N-1} I_{0} r(1-r)^{x-1}$.

Regardless of whether obsolescence occurs in year $N$ or not. The probability of obsolescence during the year is $\mathrm{e}^{-\lambda(N-1)}-\mathrm{e}^{-\lambda N}$ and the probability of no obsolescence in the year $N$ or previous years is $\mathrm{e}^{-\lambda N}$. Therefore this final possible balancing allowance has an associated probability of $\mathrm{e}^{-\lambda(N-1)}$.

It follows that the present value of the tax savings from tax depreciation $V_{\mathrm{S}}$, is given by:

$$
\begin{aligned}
& V_{s}=T\left\{\left[I_{0} r\left(\mathrm{e}^{-\lambda}\right)+I_{0}\left(1-\mathrm{e}^{-\lambda}\right)\right] \mathrm{e}^{-L k}\right. \\
& +\sum_{n=2}^{N-1} \mathrm{e}^{-(L+n-1) k}\left(I_{0} r(1-r)^{n-1} \mathrm{e}^{-\lambda n}+\left[I_{0}-\sum_{x=1}^{n-1} I_{0} r(1-r)^{x-1}\right]\left[\mathrm{e}^{-\lambda(n-1)}-\mathrm{e}^{-\lambda n}\right]\right) \\
& \left.+\mathrm{e}^{-(L+N-1) k}\left(I_{0}-\sum_{x=1}^{N-1} I_{0} r(1-r)^{x-1}\right) \mathrm{e}^{-\lambda(N-1)}\right\} .
\end{aligned}
$$

